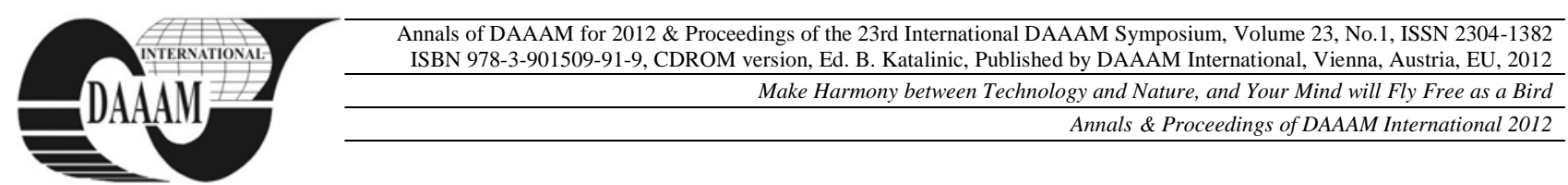

\title{
DECK DEPARTMENT LEADERSHIP THROUGH BRIDGE TEAM MANAGEMENT
}

\author{
POPESCU, C[orina]; VARSAMI, A[nastasia] E[lena]; BEJAN, R[amona]; HANZU - PAZARA, R[adu]; \\ GROSAN, V[oicu] - N[icolae] \& ARSENIE, A[ndreea]
}

\begin{abstract}
When talking about leadership on a merchant ship we have to take into consideration the fact that the ship represents a particular work environment. In this paper we shall be discussing the concept of leadership represented by the Captain, the main authority onboard a ship over the Deck Department and Engine Department. Further on, when talking about the Deck Department we shall take into consideration the fact that there is a Bridge Team that assures the safety of navigation, meaning also the safety of crew onboard and in the same time, the safety of the ship and cargo onboard. We shall also discuss how this particular Bridge Team decides on its own whether some actions should be taken or not but these decisions are taken under the close supervision of the Captain through its Standing Orders. The main purpose of this paper is to show how a ship's leader, the Captain, must ensure that the ship reaches its destination safely according to the given voyage. In this paper we are trying to show what leadership really means inside a special team, such as crew members onboard a merchant ship and what kind of leader a Captain should be.

Keywords: ship, leadership, bridge team management, Captain, safety, crew
\end{abstract}

\section{INTRODUCTION}

In order to be able to discuss the concept of Bridge Team Management we need to understand that its implementation is set to explain how a voyage is to be done safely in a way that no matter the person in charge of the navigational watch, this is deploying positively.

Generally speaking, Bridge Team Management is more than a concept. It means implementation of the way the work should be done based on navigation standards imposed by the Maritime Organizations. It basically means that all the persons involved should use in the best way possible all the human and material resources onboard a ship in order to successfully achieve the proposed goal.

Extensively, leadership on board ships represents the ability of gaining respect and authority inside a ship's crew. A ship's Captain gets respect and can show authority when the crew is convinced that he is capable of exerting the authority imposed by the job, that he has the necessary competence and knowledge, that he understands different situations and he is capable of solving them and that he is ready to lead fair and decisively.

Therefore, studies showed that without authority and respect it is difficult for a Captain to influence crew's behaviour, including it's response in case of need. If the person in charge, the leader, is not ready for this, all the crew members will search to find another leader, and this leads to authority undermining.

\section{BRIDGE TEAM MANAGEMENT CONCEPT}

Bridge Team Management is meant to explain the way a voyage must be organized in safety conditions so no matter who is the person in charge, the voyage is done positively. Modern electronic systems for navigation and current technical equipment for operating navigation are substituting human work, but in the same time they require a superior standard of training for the navigation personnel.

The concept of Team Management implies assuming the role of a leader by all members of the team, not only by a single person. Taking this into consideration, each member of the team must have the necessary technical knowledge but also administrative qualities of the available human resources.

If a leader onboard a ship is not ready to exert his leadership function, the crew members will look for another leader, situation that leads to authority disruption. Another situation that could lead to Captain's authority disruption onboard a ship is determined by the Company's intense implication in ship's management and breaking consciously direct orders given by the Captain onboard the ship.

\subsection{Types of Leaders (Captains) Onboard Ships}

Onboard merchant ships there can be identified two types of leaders (Captains). The first type is leaders (Captains) who act out of their own interests, and who assume that others do the same. They are calculating and use complex strategies to conquer resistance, and to achieve their aims. The other type is leaders (Captains) who have a sense of cultural belonging. They act according to the Shipping Company's practices of mutual understanding of what is true, reasonable, natural, and right in organizations. The first type of leader (Captain) acts from the logic of consequences: leadership choice is a conscious, consequence-driven action and the leader's (Captain's) motivation is self-interest. This logic tends to see leaders as interacting autonomous and self-interested. They are also supposed to be sensitive to incentive instruments, which mean that the way to steer the motivation of leaders is to align their self-interests with the interests of the Shipping Company. The other type of leader acts from the logic of appropriateness: leadership choice is based on what is appropriate in relation to 
Shipping Company's rules and cultural norms associated with the leader's (Captain's) own identity, and the leader's (Captain's) motivation is commitment to this sense of self. This logic is related to self-knowledge (what type of leader am I?), and the capability to act from this insight. Leaders (Captains) conduct themselves according to duties and to that which means something within a cultural and social context. One of the major instruments for motivating leaders (Captains) to use the logic of appropriateness is accountability. To make leaders (Captains) accountable is to make them more careful in the definition of the situation, and more sensitive to social pressures and standards of appropriate behaviour associated with their roles. Another major instrument is the adapting capacity through experiential learning. For this to happen, accountability must be linked to accounts from which leaders (Captains) can learn (for example, what went wrong and why) and which will be remembered; necessitating investing in records and intelligent retrieval. In addition, the information must be enriched by the experience of others.

In their pursuit of instrumental rationality, leaders (Captains) are assumed to be capable of using judgment informed by experience and analysis; that is; instrumental rationality requires a mixture of knowledge gleaned from an intimate awareness of the fine details of the specific organizational context and knowledge gleaned from general analytical thinking. Such knowledge cannot be collected by a single mind. This is because the knowledge of the circumstances in which the leadership must act never exists in a concentrated or integrated form, but solely as the dispersed pieces of incomplete knowledge that separate the leadership process; i.e., persons in leadership roles hold related and relevant knowledge in different locations. Thus, leaders (Captains) need to collaborate in order to process diverse information.

Leaders (Captains) follow rules, and discipline themselves through a sense of self that allows them to achieve a desired end that might otherwise be attainable only with difficulty. Shipping Company's practice reflects this notion. When there is a decision to develop an organizational culture inside the Shipping Company, it is to bring about belongingness and to create identity as a framework for choice, action and interaction. The more the codes of rights and duties are internalized, the stronger the effect the culture has on leadership action. From this view, leaders can be cultural architects who develop and support norms that promote exchange and combination of knowledge in ways that increase creativity and new thought. One such norm is leadership cooperation. Leadership cooperation as a norm is to a high degree supported by a "soft", social logic of appropriateness: the voluntary transfer of information is an act of trust that resides in identity and reciprocity. Leadership cooperation as a norm is to a low degree supported by a "hard", rational logic of command-andcontrol which sees leaders, and their relationships, as motivated by self-interest: leaders (Captains) exchange and combine information because they are commanded and paid to do so. The discussion reveals that leadership views, or logics of action, affect creating, transferring and using knowledge in organizations. This is especially so regarding transferring. Different logics of action create different conditions for transferring.

\subsection{Leadership through Bridge Team Management}

Leaders (Captains) can create their own leadership style, according to their own personality, but there are several common elements to all the leadership styles that help imposing authority:

- Confidence in own taken decisions and actions;

- Mistakes acceptance when this is obvious;

- Demonstrating respect for others;

- Gaining respect through accomplished actions.

Authority onboard a ships can be disrupted if the Captain exerts its power through:

- Forcing respect from the crew members;

- Using his position in the scope of threatening;

- Refusing collaboration with the rest of the crew;

- Interfering excessively in the ship's onboard activities;

- Ignoring Company's orders and indications.

An efficient management of the navigation bridge coming from the leader (Captain) means correct use of the available human resources and promoting a good communication inside the bridge team. Junior officers are often concerned that they might be inconveniencing the Captain as Leader by calling him to the bridge. However, Captains need to be called as soon as possible if a difficult situation is developing, as he is most likely to be able to help the Officer on Watch resolve the problem. Captains have more confidence in Officers on Watch who demonstrate their willingness to call the Captain than those Officers on Watch who allow dangerous situations to develop. The Officer on Watch, by calling the Captain early, will be able to learn from the experience of the Captain when he comes to the bridge. The Officer on Watch has a duty to call the Captain early and this must be the guiding principle at all times. The Captain has the ultimate responsibility for the safe and efficient operation of the ship. He is likely to be the most experienced navigator on the ship and will probably have dealt with most situations before. The Officer on Watch therefore has a duty to comply with his orders and to keep the Captain informed of progress. The Officer on Watch should ask the Captain about any unusual or potentially dangerous occurrences.

The Captain's appearance on the bridge does not relieve the Office on Watch of his responsibilities. The Officer on Watch is still in charge of the watch until the Captain formally takes charge. It must be made clear immediately who is in charge of the watch. To avoid any confusion the Officer on Watch must assume he is in charge of the watch unless formally relieved by the Captain. Despite the requirement to notify the Captain immediately in certain circumstances, the Officer on 
Watch should, in addition, not hesitate to take immediate action for the safety of the ship, where circumstances so require.

The number of members of the bridge team is established by the Captain. For establishing the component of the bridge team, the Captain must take into consideration the following main factors: visibility, sea state, general meteorological conditions; the density of the traffic and other activities that appear in the area transited by the ship; the attention that must be paid when navigating through Traffic Separation Scheme or other systems for controlling the traffic; extra activities imposed by the ship's characteristics and anticipated manoeuvres that are to be done; professional experience and qualities of the officers on watch; current activities onboard the ship, including the anticipated volume of radio communications; operational level of the navigational equipment; ship's manoeuvre capacity; ship's dimensions and the observed horizon opening from the bridge.

Cultural differences represent the fundament of communication and imply development of understanding abilities between different nationalities. Cultural differences become visible when we get in contact with people of different nationalities. This is a situation frequently met onboard ships with multinational crews. A good leader (Captain) knows how to overcome the difficulties that arise from different culture crew members working together. He should first try to understand each culture met onboard and then try to work together and create a bond. What it is considered appropriate in one culture could be, most of the times, inappropriate in another culture. Misunderstandings caused by cultural differences appear when a person of a certain culture wants to force his own point of view to another person who belongs to a different culture, with different principles. Wrong interpretation is the main element that appears whenever we want to force to another person our own concepts. In the absence of a good knowledge of the cultural characteristics of another person, it is preferable to have a diplomatic approach of certain aspects that are related to own culture.

Each person develops a certain personality in the spirit of the culture he/she comes from. That's why, every time there is an interaction with another cultures onboard ships, it is indicated for the Captain, in the first phase, to discover cultural similarities and to obtain the answer for the existent differences.

The leader (Captain) has to also take into consideration that when he meets persons with a similar culture, he has to assume the risk that his actions might not be interpreted adequately and this could lead to a negative response from the others. For the Captain, but also for the entire crew it is safer to assume the existence of major cultural differences until the discovery of cultural similarities. The growth of cultural awareness means to observe positive aspects but also the negative ones that appear inside the cultural differences. Cultural diversity could represent a source of problems for the leader (Captain) especially in a field like the maritime one where there is a constant need for collaboration.
Also, cultural diversity could be an advantage if the leader (Captain) manages to find ways of cultural approach and understanding especially in the scope of development.

Correct approach of cultural differences by a leader (Captain) can be done by assuming several concepts like: admit that you don't know; think it before; sympathize; make sure that you have been correctly understood; accept diversity.

\section{TRAINING ONBOARD AND COMMUNICATION}

Before the ship leaves for a voyage the Captain must inform the bridge team about the specific elements of the journey like:

- Route plan;

- Requirements that must be fulfilled by the bridge team during the voyage;

- Discussing about the particularities of the route and identifying the sensible points;

- Defining the way of work on the bridge in order to assure the necessary level of safety.

Communication inside the bridge team must be clear. Communication between members of the bridge team who talk different languages, especially with crew members who are not licensed, must be done in a common language, and that is Maritime English. When there is a pilot onboard the ship, the same rules for communication are applied.

The ability of the personnel onboard to coordinate their activities and to efficiently communicate between them is vital in emergency cases. Especially for the leader (Captain) it is important to be able to communicate efficiently with the members of the bridge team whenever it is necessary but in most of the cases it is important for the Captain to be able to transmit his intentions and orders to his crew members, especially in cases of emergency. No matter if the ship is underway or if it is doing an entrance in the port manoeuvre the bridge team must function as an upright team.

A bridge team with a well explained plan by the Captain and in the same time well understood plan, will possess a good response in case of an emergency. Where the members of the bridge team are able to anticipate a dangerous situation and to recognise the development of an error chain, they will have the capacity of taking the necessary actions for avoiding that certain situation and correcting the committed errors.

If the Captain is making a good schedule of the ship's voyage, the bridge team will have a better control of the ship's evolution and will avoid the appearance of unpredicted events due to the configuration of the navigation area. The way that the cancelling of the initial plan and applying the emergency one is being done, is related to the experience of the bridge team and of the Captain and the appearance of unpredicted problems. Whenever it is possible, when the voyage is completed successfully, the Captain must discuss with the bridge team about the way the voyage was planned and 
executed, especially about the observed weak points. This kind of discussions lead to correction of the initial plan and obtaining a better voyage plan that can be used next time for the same route. Motivation for the activity done onboard a merchant ship must come from oneself and cannot be imposed. It is the leader's (Captain's) responsibility to create the proper conditions for one's motivation to be encouraged.

A valuable quality of an organization like it is represented by a merchant ship is given by the team work and this is growing if the people forming a team are recognized their values, limitations and competencies, and in the same time organizing work on the bridge must lighten the qualities of each member of the team. Working in a team and free circulation of information professionally encourages development of relations between the bridge team, Captain and pilot. Communication on the bridge must be done open, with no restrictions caused by the difference of positions occupied in chain of command by the people involved in that particular activity. The open communication that mainly must be ensured by the Captain on the bridge but also in other compartments of the ship also includes new members' training and familiarization with the elements and particularities of the ship.

Procedural rules drawn by the Captain must be written and they will reflect the Captain's specific requirements and particular circumstances in which the ship might find itself, its commercial scope and the bridge team's professional experience. These orders and instructions drawn by the Captain must not conflict with the general rules related to ship's safety management system. Besides the general procedural orders, specific instructions must exist for special circumstances cases.

It must be clear stated in the company's safety management system the Captain's duties regarding taking decisions about ship's safety and their responsibilities, but also regarding the possibility of taking over the officer's duties when this is necessary. The Captain must not be forced by the company in any way in taking decisions regarding ship's safety and safety of navigation, especially in rough weather and rough seas conditions.

The bridge team must know very well what they have to report to the Captain in normal conditions of navigation, the requirements regarding complete information of the Captain, but also the circumstances in which the Captain must be called on the bridge. The Captain must clearly state the tasks, and these must be limited to those that can be effectively accomplished and also their priority must be clearly established. The members of the team must be asked and they have to confirm that they have understood the tasks and responsibilities they have been assigned. Periodical reports of events that occurred during fulfilment of tasks represent one of the best means to monitor performance of members of a bridge team and to detect any degradation in executing the watch.

\section{CONCLUSION}

Crew's safety must represent a priority for the leader (Captain) onboard a merchant ship and this must be proven by his actions that eventually lead to a safe work environment. Captain's implication in ensuring the crew's safety is vital especially because operational pressure is not to compromise the ship's safety. This will prove the true meaning of team work adding a plus of trust in their leader.

Important elements in creating a safe climate by the Captain are:

- Ensuring safety criteria as an integral part of the daily activities, including meetings and discussing personal problems of the crew members;

- Clear exertion of actions that lead to improving safety level onboard the ship.

Onboard a ship, leadership is a requirement for organizational growth of the crew's activity. In the shipping industry there is a constant need for identifying and cultivating future leaders who have the potential to excel in critical leadership roles onboard merchant ships. Ships need leaders (Captains) who can be a force for coherence and unity, and who can contribute to efficiency - associated with exploitative and explorative organizational learning. To be a good leader means to impose respect and authority inside a crew, to exert the necessary authority, to possess the necessary competencies and knowledge, to be able to understand different situations and solve them in a successful way, to be able to have an open communication and also to be ready at any moment to rule correctly and conclusively.

\section{REFERENCES}

[1] Barsan, E. \& Muntean, C. (2010). Combined Complex Maritime Simulation Scenarios for Reducing Maritime Accidents Caused by Human Error, Proceedings of the WSEAS 3rd International Conference on Maritime and Naval Science and Engineering, 3$5^{\text {th }}$ September, Constanta, Romania, ISSN 1792-4707 88, ISBN978-960-474-222-6, pp. 88-93, Published by WSEAS Press, Athens Greece

[2] Barsan, E. \& Muntean, C. (2008). "E-navigation requires new methods of training for deck officers", 9th General Assembly of International Association of Maritime Universities, 19-22th October, San Francisco, U.S.A., ISBN 978-0-615-25465-4, pp. 29-40, Published in World Maritime Excellence, Publisher Calmar, U.S.A

[3] Day, D.V. (2000). "Leadership development: A review in context", Leadership Quarterly, 11, pp. 581-613.

[4] International Chamber of Shipping.(1998). Bridge Procedures Guide, Marisec Publications, London

[5] March, J.G. and Weil, T. (2005). On Leadership, Blackwell Publishing, Cambridge

[6] Milliken, F.G. and Martin, L. L. (1996). "Searching for common trends: Understanding the multiple effects of diversity in organizational groups", Academy of management Review, 21, 402-433

[7] Stewart, R. (1989). "Studies of managerial jobs and behaviour: The way forward", Journal of Management Studies, 26, pp. 1-10 